\title{
Bryozoan growth and environmental reconstruction by zooid size variation
}

\author{
Beth Okamura $^{1, *}$, Aaron O'Dea ${ }^{2,3}$, Tanya Knowles ${ }^{4}$ \\ ${ }^{1}$ Department of Zoology, Natural History Museum, London SW7 5BD, UK \\ ${ }^{2}$ Center for Tropical Paleoecology and Archeology, Smithsonian Tropical Research Institute, Apartado 0843-03092 Panamá, \\ República de Panamá \\ ${ }^{3}$ Department of Earth and Ocean Sciences, University of British Columbia, Vancouver, British Columbia V6T 1Z4, Canada \\ ${ }^{4}$ Department of Earth Science and Engineering, Imperial College London, London SW7 2BP, UK
}

\begin{abstract}
The modular growth of cheilostome bryozoans combined with temperature-induced variation in module (zooid) size has enabled the development of a unique proxy for deducing seasonal temperature regimes. The approach is based on measures of intracolonial variation in zooid size that can be used to infer the mean annual range of temperature (MART) experienced by a bryozoan colony as predicted by a model of this relationship that was developed primarily to infer palaeoseasonal regimes. Using the model predictions effectively requires a highly strategic approach to characterise the relative amount of within-colony zooid size variation (by adopting random or very systematic measurements of zooids that meet a stringent set of criteria) to gain insights on temperature variation. The method provides an indication of absolute temperature range but not the actual temperatures experienced. Here we review the development of, support for and applications of the zooid size MART approach. In particular, we consider the general issue of why body size may vary with temperature, studies that validate the zooid size-temperature relationship and insights that have been gained by application of the zooid size MART approach. We emphasise the potential limitations of the approach, including the influence of confounding factors, and highlight its advantages relative to other proxies for palaeotemperature inferences. Of prime importance is that it is relatively inexpensive and quick and allows a direct estimate of temperature variation experienced by an individual colony. Our review demonstrates a strong and growing body of evidence that the application of the zooid size MART approach enables robust interpretations for palaeoclimates and merits broad recognition by environmental and evolutionary biologists and climate modellers.
\end{abstract}

KEY WORDS: Cheilostomes $\cdot$ Mean annual range of temperature $\cdot$ MART $\cdot$ Body size-temperature relationship $\cdot$ Palaeoclimates

\section{INTRODUCTION}

Patterns of growth in plants and animals have long been used to gain insights into past environments. Variable accretion of structural material in trees, fish otoliths and the shells of bivalve or gastropod molluscs, for example, can be used to retrospectively extract ambient environmental conditions such as rainfall, temperature or food availability (e.g. Falcon-Lang 2005, Zazzo et al. 2006, Hallmann et al. 2009). Organismal attributes that favour such analyses include a continuous record of growth and the sequential development of discrete and measurable features that vary consistently with respect to a single environmental variable and remain fixed, thereby permitting the retrieval of environmental conditions relevant to particular time periods. Benthic colonial invertebrates can provide an especially appropriate system for such retrieval, since, with some exceptions (e.g. sponges), they comprise distinct, individual modules (zooids) that are produced iteratively throughout the lifetime of the colony. The sclerochronological analysis of modular 
growth can provide inferences for both intra- and interannual environmental variation, information that is not readily available from analyses of short-lived, unitary organisms that are commonly used as proxies, such as foraminifers or ostracodes. Furthermore, coloniality is often associated with polymorphism, with modules specialised for different functions within a colony. These attributes, viz. modular iteration, polymorphism and individual colony longevities ranging from months to many years, may enable joint insights into environmental conditions and associated life history variation (O'Dea \& Okamura 2000a, O'Dea \& Jackson 2002). Such insights are generally difficult to achieve through investigations of longer-lived unitary organisms, such as bivalves or brachiopods, since the morphologies of these organisms do not readily provide a record of functional allocation during their lifetime. Surprisingly, however, the unique contribution of colonial invertebrates for retrospectively deducing environmental and life history variation has not been widely recognised.

Bryozoans are colonial, suspension-feeding invertebrates that are common members of benthic assemblages (McKinney \& Jackson 1989). There are some 6000 described extant species of bryozoans (Gordon et al. 2009), most of which belong to the order Cheilostomata. Colonies of cheilostomes comprise asexually budded zooids that are reinforced by skeletal walls composed of calcitic and/or aragonitic carbonate (Rucker \& Carver 1969, Smith et al. 2004). Typically, cheilostomes display zooid polymorphism (McKinney \& Jackson 1989). The majority of zooids are specialised for feeding (autozooids), whilst a smaller proportion function in reproduction (ovicells) and defense (avicularia). The carbonate skeleton ('zooecium') confers preservation of colony features, including zooid polymorphism, and bryozoans are well represented in the fossil record (McKinney \& Jackson
1989). Once the skeletal walls of a new zooid are secreted, there is no further expansion of zooid surface area (O'Dea \& Okamura 2000b). This gives the zooid a determinate size that has been shown to be controlled to a significant extent by the ambient water temperature at the time the zooid was produced. Bryozoan colonies therefore record the range of temperatures experienced during their lifetime as intracolonial variation in zooid size (Fig. 1). Such temperature-induced variation in size is also observed in unitary animals and is generally known as the 'temperature-size rule' (Atkinson 1994).

The above-mentioned features make cheilostome bryozoans unique amongst colonial taxa in offering opportunities for inferring environmental conditions and biotic responses in the present day as well as over geological time. Other colonial taxa such as corals, hydroids, ascidians and other non-cheilostome bryozoans either do not produce carbonate skeletons, show indeterminate growth of their polyps or zooids, or exhibit little to no polymorphism and therefore preclude gaining additional insights on how life histories may respond to environmental conditions.

Recognition of the unique opportunities afforded by cheilostome bryozoans for the retrieval of environmental information led to the development of a method that allows the estimation of the mean annual range of temperature (MART) based on variation in zooid size within cheilostome colonies. The method is based on using model predictions for how zooid size varies with MART and thus requires that zooids meet a stringent set of criteria, in keeping with assumptions of the model, and that a strategic sampling protocol is adopted to target appropriate zooids randomly or very systematically. The method informs on absolute seasonal variation in temperature but does not indicate the actual temperatures. Thus polar and tropical bryozoans will converge on similar low MART values.
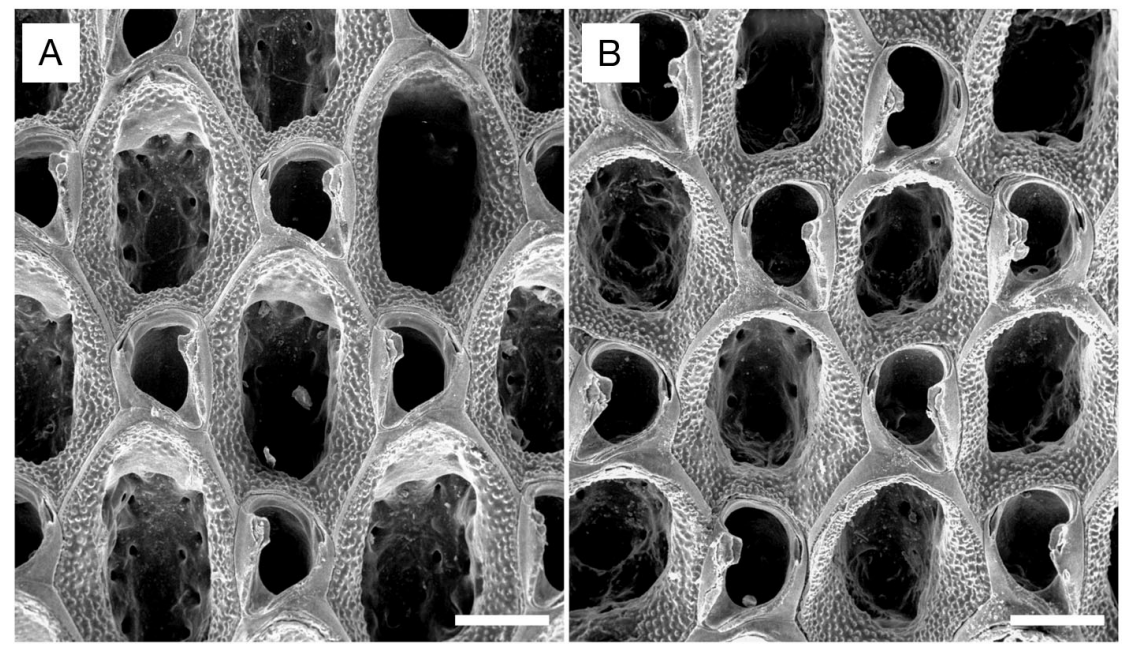

Fig. 1. Cupuladria exfragminis. Seasonal variation in zooid size. Scanning electron micrographs of a recent colony from the Gulf of Panama. Size difference between zooids that developed during (A) upwelling (cold) and (B) non-upwelling (warm) conditions. Same magnification for the purpose of comparison. The skeletal walls of both autozooids (large orifices) and avicularia (small orifices) are evident. Scale bar $=150 \mu \mathrm{m}$. Photos by R. Dewel 
In this paper we describe this zooid size MART approach, review studies that validate the zooid size-temperature relationship on which the technique depends and summarise research that has made use of the approach in order to demonstrate the insights that can be gained by its adoption. We also emphasise the potential limitations of the zooid size MART approach, describe confounding factors that must be borne in mind and suggest directions for future studies. However, because the approach is based on temperatureinduced variation in zooid size, we first describe the temperature-size rule and address the mechanism(s) that may underlie the temperature-size relationship. Examination of these issues leads us to conclude that the zooid size MART approach provides a unique and independent proxy that will enable more robust interpretations when incorporated as part of the toolkit used for environmental and evolutionary studies.

\section{VARIATION IN BODY SIZE WITH TEMPERATURE}

The inverse relationship between zooid size and temperature conforms to a general pattern observed in ectotherms known as the 'temperature-size rule' (Atkinson 1994). This pattern is expressed as phenotypic plasticity in response to temperature variation demonstrated by negative thermal reaction norms. As with any 'rule', there are instructive exceptions, but the overall weight of evidence for the temperaturesize rule (Atkinson 1994, Angilletta et al. 2004, Kingsolver \& Huey 2008) lends additional and important support for temperature-driven variation in zooid sizes. What has been unclear, however, is what mechanisms may underlie this nearly universal relationship, whether there exists an adaptive basis for thermal sensitivity in body size, and whether the mechanisms and/or adaptive explanations are inclusive across taxa. Central to this issue is the association of the temperature-size rule with a life-history puzzle (Berrigan \& Charnov 1994): that good conditions result in faster growth to a larger size but that temperature has contradictory effects on growth and size, with higher temperatures driving faster growth to a smaller size.

Hypotheses proposed for the temperature-size rule include both adaptive and non-adaptive scenarios (Atkinson 1994, Angilletta et al. 2004). However, demonstrations that the shapes of thermal reaction norms can readily evolve in response to selection (see Kingsolver \& Huey 2008 for review) suggest that selection maintains the temperature-size rule. A problem common to many of the hypotheses proposed to explain the temperature-size rule is that they are too restrictive to apply to the diversity of taxa that follow the rule (see Angilletta et al. 2004, Kingsolver \& Huey 2008 for re- cent review). Mechanistic explanations have included: (1) the production of smaller adult stages because developmental rate is more strongly influenced by increasing temperature than growth rate (van der Have \& de Jong 1996); (2) the related hypotheses that cell (van Voorhies 1996, Woods 1999) or body (Chapelle \& Peck 1999) size is limited by oxygen diffusion.

Atkinson et al. (2006) recently addressed the explanation that the temperature-size relationship may relate to oxygen concentrations by examining the thermal responses of the bryozoan Celleporella hyalina to 2 temperatures $\left(10\right.$ and $\left.18^{\circ} \mathrm{C}\right)$ and 2 oxygen concentrations (21 and $10 \%$, representing normoxia and hypoxia, respectively). They found that smaller zooids were produced under hypoxia regardless of temperature (although size was also influenced directly by temperature), providing evidence for the expected adjustment of size in response to oxygen requirements. This adjustment is anticipated because increasing temperatures increase metabolic rates and thus oxygen demands, but these metabolic oxygen demands increase faster with temperature than diffusion in the organism's oxygen uptake and transport system. Smaller size will therefore decrease diffusion distances and increase the relative surface to volume ratios for oxygen uptake. In addition, size variation may regulate respiratory activity, with a decrease in size reducing activity at higher temperatures via reductions in mitochondrial volume density and in cristae density (see review by Atkinson et al. 2006).

Atkinson et al. (2006) also obtained evidence that the temperature-size rule is not a fundamental response of cells. Larval parenchyma cells were larger at the lower temperature, but temperature had no effect on the size of epithelial cells of the tentacle. Similar results have been obtained in other empirical studies that have shown that larger body sizes at lower temperatures can be caused by an increase in cell size in some systems (e.g. in nematodes or some Drosophila populations) but not in others (including other Drosophila populations; see Angilletta et al. 2004 for review). As mentioned earlier, Atkinson et al. (2006) also found that an inverse temperature-size relationship characterised zooids, but this was not the case for tentacle length. Thus, the temperature-size rule did not apply universally at the cell or organ (e.g. tentacle) level.

Their results led Atkinson et al. (2006) to propose that temperature-induced size changes at different levels of organisation are part of a range of acclimation mechanisms, including variation in body size, that will optimise functional capacity (e.g. of mitochondria and tissues) to maintain scope for aerobic activity. They suggest that these acclimatory processes occur within a temperature range whose limits are determined by when oxygen partial pressures of body fluids fall. This 
occurs at the so-called 'pejus' limits, when the capacity of oxygen supply mechanisms is unable to support oxygen demand (Pörtner 2002). Thus, at high temperatures, excessive oxygen demand results in insufficient oxygen levels in the body fluids, while at low temperatures, the aerobic capacity of mitochondria may become limiting. Beyond these limits aerobic scope disappears, and the adoption of anaerobic metabolism will support time-limited survival. If these acclimatory responses to maintain scope for growth underlie the temperature-size rule, they could at least in part account for the puzzle of the inverse temperature-size relationship despite increased growth rate with warmer temperatures.

As discussed below and exemplified by the study of Atkinson et al. (2006), cheilostome bryozoans demonstrate intraspecific thermal sensitivity that reflects the temperature-size rule. They also demonstrate variation in zooid size within (see 'Evidence for relationship between temperature and zooid size') and among closely related species (e.g. species of Haplopoma; Ryland 1963) living in geographic regions that are characterised by different temperature regimes. The extent to which the latter reflects phenotypic plasticity versus selection requires investigations of thermal reaction norms. It should be noted that the zooid size approach to MART is not complicated by these issues since it is based on intracolonial zooid size variation. However, the occurrence of the temperature-size rule at the modular level amongst colonial organisms raises the question of the adaptive significance of body size when environments change over the lifetime of colonies. Because zooids remain fixed in size, any adaptive basis for size at the time of budding will be ephemeral in seasonal environments. For bryozoans, an adaptive basis for phenotypic plasticity in zooid size may nevertheless apply if at least some regions of a colony are in optimal condition as a result of zooid-size matching to the prevailing thermal regime. Alternatively, smaller zooids may simply result if the developmental rate is more strongly influenced by increasing temperature than growth rate (van der Have \& de Jong 1996).

\section{ZOOID SIZE MART APPROACH}

The zooid size MART approach is based on a predictive model that allows seasonal variation in temperature regimes to be estimated from the empirically derived relationship between intracolonial zooid size variation and the MART (O'Dea \& Okamura 2000b). The model was developed by undertaking morphometric analyses of 157 colonies of 29 cheilostome species ranging from tropical to polar regions and is based on a regression of the mean coefficient of variation $(\mathrm{CV})$ of zooid size and the MART with $95 \%$ confidence limits within $\pm 1^{\circ} \mathrm{C}$ across the entire temperature range (see Fig. 2c in O'Dea \& Okamura 2000b). Zooid size was estimated by measuring the maximum distance between the proximal and distal skeletal walls, to estimate zooid length, and the maximum distance between the lateral skeletal walls, to estimate zooid width (Fig. 2). These maximum distances infer growth along a straight line trajectory aligned perpendicular to zooid margins that are farthest apart (see Fig. 2). Zooid frontal area is then calculated as the product of zooid length and width. The mean maximal difference between summer and winter temperatures over a number of years for the depths at which the bryozoans were collected (see O'Dea \& Okamura 2000b for further discussion) was used to estimate MART. Algebraic rearrangement of the regression provides a means of predicting MART as: MART $=-3+0.745 b$, where $b$ is the mean intracolonial $\mathrm{CV}$ of zooid size.

The dependability of the zooid size MART approach is a function of several factors, including the data that were originally used to develop the model, variation in response to MART amongst taxa, other agents of zooid size variation and rigour in applying the approach. In developing the model, data on zooid sizes were required to meet a stringent set of criteria. Zooid size values were based on 20 randomly selected autozooids per colony. However, to minimise variation due to factors known to influence zooid size, the autozooids were required to show uninhibited growth (i.e. were not perceptibly deformed), to be part of the basal series of zooids (i.e. not frontally budded) and to be located outside of the zone of astogenetic change (Fig. 3). This zone is created during the early growth of colonies, when zooid generations show pronounced incremental increases in size. Beyond this zone zooid sizes are relatively stable (Boardman \& Cheetham 1969). There were also criteria for choosing colonies and species for measurement. For colonies, these included offering at least 30 ontogenetically complete autozooids and avoiding measuring colonies whose shapes were compromised by e.g. irregularities in the substratum or observable competition from other organisms. For species these included: offering clearly delimited zooid margins for measurement; no evidence of distortion in dried material; avoidance of 'spot' colonies that undergo determinate growth to a very small size (Winston \& Håkansson 1986, Bishop 1989); the availability of at least 5 replicate colonies per species. The CVs were averaged for each species at each locality. Since the model uses estimates of zooid size to infer seasonal temperature regimes, it is important that, as far as possible, these estimates are based on applying a similar set of criteria to those that were used to develop the model. 


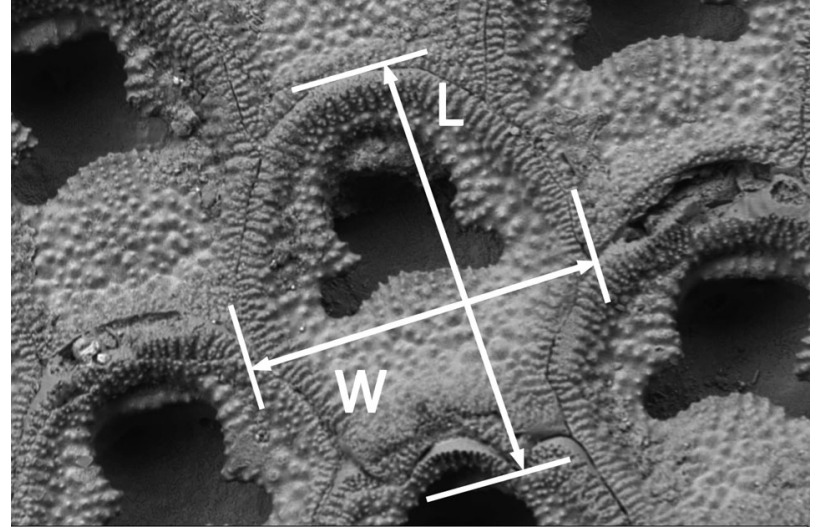

Fig. 2. Floridina regularis. Scanning electron micrograph of a colony from the Yorktown Formation (Chuckatuck, Virginia, USA) showing length (L) and width (W, $150 \mu \mathrm{m})$ of a zooid. Measurements are based on maximum dimensions of zooids that meet the criteria for zooid size mean annual range of temperature (MART) analysis, see Table 1

O'Dea \& Jackson (2002) later developed an alternative method for zooid size MART analysis. Instead of conducting random sampling of 20 zooids per colony, they undertook highly systematic sampling of zooids that met the above criteria. This entailed measuring sequential generations of disto-laterally budded zooids in cupuladriid bryozoans (Fig. 4). They characterised 4 such zooid profiles per colony and found that the mean maximum and minimum values correlated well with the MART experienced by the colonies living in contrasting seasonal regimes. This zooid profiling approach requires particular care to avoid measuring the

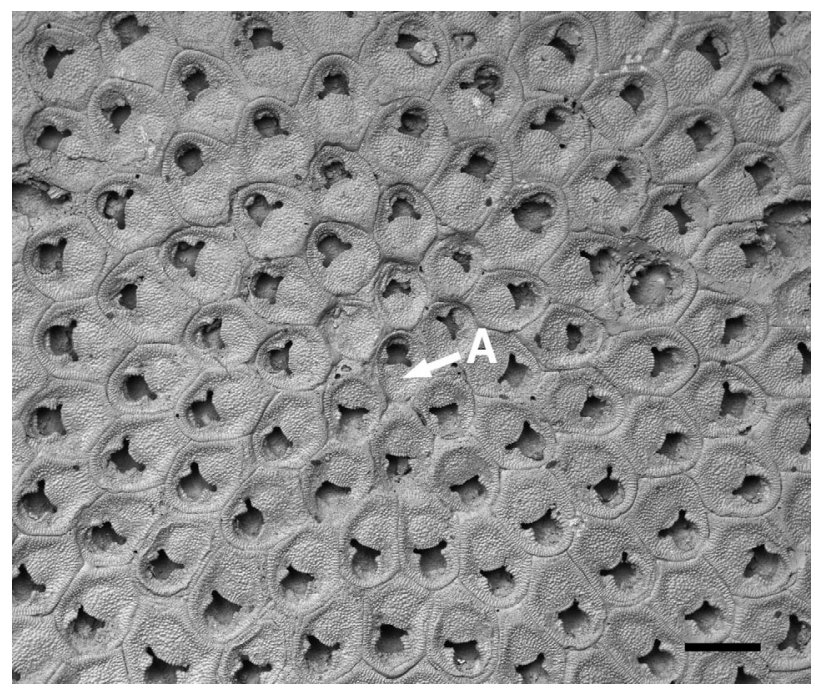

Fig. 3. Floridina regularis (as in Fig. 2). Zone of astogenetic change. Scanning electron micrograph of ancestrula (A) and region of early colony growth showing a gradual increase in zooid size throughout the first few generations. Scale bar $=$ $250 \mu \mathrm{m}$ somewhat smaller zooids that occur at bifurcations or just distal to bifurcations in the normal budding series. Such zooids are encountered more frequently near the centre of the colony, as row bifurcations allow zooids to populate space as the colony extends radially. In such cases, the path of the profile was altered (Fig. 4). This zooid profiling technique has the advantage over randomly sampling zooids for MART estimation in that recording continuous changes in zooid sizes allows the demonstration of annual growth increments and insights on growth rates and colony longevity (e.g. Fig. 5 of O'Dea \& Jackson 2002). Table 1 summarises the set of rules that must be met when conducting either random or systematic measurements of zooids for zooid size MART analysis. These rules reflect the various criteria mentioned above.

\section{EVIDENCE FOR THE RELATIONSHIP BETWEEN TEMPERATURE AND ZOOID SIZE}

The zooid size MART approach is founded upon the negative relationship between zooid size and temperature that has been demonstrated in both controlled laboratory and field situations and over spatial and temporal scales. In the following 4 subsections we review and evaluate the growing body of evidence that supports this relationship.

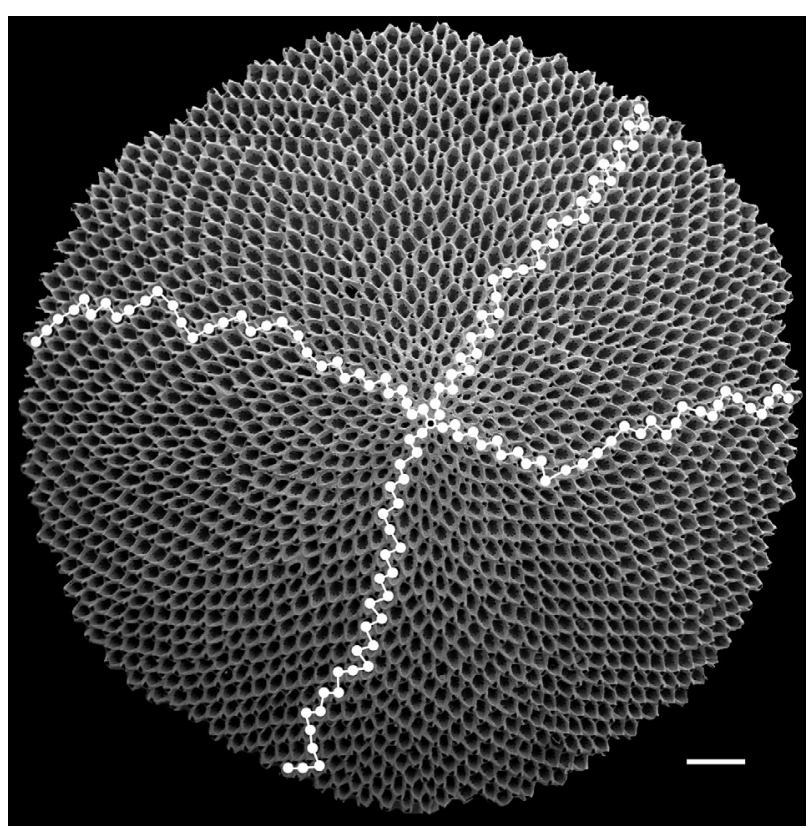

Fig. 4. Cupuladria aff. biporosa. Zooid size profiling. Scanning electron micrograph. White lines $=$ paths of 4 profiles from the central ancestrula to the colony margin. Dots = zooids chosen for measurement according to strict rules as outlined in text. Scale bar $=1 \mathrm{~mm}$. Reprinted from O'Dea \& Jackson (2002) with permission from Elsevier 


\section{Laboratory studies}

Controlled laboratory studies have consistently demonstrated that zooids increase in size at lower temperatures. Menon (1972) showed decreases in both the lengths and widths of zooids of Electra pilosa and Conopeum reticulum as laboratory temperatures increased (temperature regimes: $6,12,18$ and $22^{\circ} \mathrm{C}$ for E. pilosa; 12,18 and $22^{\circ} \mathrm{C}$ for C. reticulum). Hunter \& Hughes (1994) found that Celleporella hyalina produced significantly smaller zooids at $18^{\circ} \mathrm{C}$ than at $8^{\circ} \mathrm{C}$ and that this response occurred irrespective of food supply (10 vs 100 cells ml $^{-1}$ of Rhodomonas baltica). A later study provided further and independent evidence for an inverse relationship between temperature and zooid size in $C$. hyalina, with autozooids being smaller when colonies were reared at $10^{\circ} \mathrm{C}$ than at $18^{\circ} \mathrm{C}$, even when the partial pressure of oxygen was altered from normal to hypoxic conditions (Atkinson et al. 2006). This study also demonstrated that, like length and width, autozooid volume varies inversely with temperature. Amui-Vedel et al. (2007) found that Cryptosula pallasiana produced longer and wider zooids at $14^{\circ} \mathrm{C}$ than at $18^{\circ} \mathrm{C}$ under equal food concentrations (100 cells $\mathrm{ml}^{-1}$ of $R$. baltica). The aforementioned studies were all conducted on temperate encrusting species that were growing on glass or plexiglass slides whose flat surfaces will minimise variation in zooid dimensions arising from topographic complexity.

O'Dea et al. (2007) took advantage of the naturally high rates of colony cloning in the free-living, tropical species Cupuladria exfragminis to observe the effects of temperature upon zooid size amongst genetically identical clones. Colonies from the Gulf of Panama were halved and the resulting clonal replicates exposed in culture to either $29^{\circ} \mathrm{C}$, the normal temperature for the Gulf of Panama, or $24^{\circ} \mathrm{C}$, a temperature commonly observed during episodes of upwelling. The $5^{\circ}$ reduction in temperature resulted in a $25 \%$ increase in zooid surface area. When normal, warmer temperatures were restored, new zooids reverted to the smaller size associated with $29^{\circ} \mathrm{C}$.

\section{Growth in the field}

Temperature-induced variation in zooid size has been directly investigated in the field in the encrusting species Conopeum seurati. This was achieved by measuring the maximum lengths and widths of focal colonies that colonised glass slides on 19 occasions over $15 \mathrm{mo}$ in the Severn Estuary and conducting simultaneous measurements of temperature, salinity and food availability, as estimated from chlorophyll $a$ (chl a) concentration (O'Dea \& Okamura 1999). Sampling intervals were approximately biweekly during periods of rapid growth but less frequent in winter when growth slowed considerably. General linear model analysis revealed that temperature consistently accounted for most of the variation in zooid size $(40.5 \%)$ with larger sizes occurring at lower temperatures (e.g. Fig. 1). Salinity, colony identity (genotype) and an interaction between temperature and salinity also influenced zooid size (by 21.1, 3.2 and 22.0\%, respectively). Factors that had no significant effect on zooid size were food availability (chl a concentration), colony growth rate and the reproductive status of colonies based upon the presence or absence of embryos, eggs or oocytes (O'Dea \& Okamura 1999).

Other studies that have measured zooid size variation in the field were conducted on colonies established on natural substrata. Lombardi et al. (2006) demonstrated that the upright bifoliate species Pentapora fascialis produces larger zooids during the colder winter than during the warmer summer near Plymouth (UK) and Tino Island in the Mediterranean. In contrast,

Table 1. Rules for choosing zooids, colonies and species appropriate for zooid size mean annual range of temperature (MART) analysis on cheilostome bryozoans

\begin{tabular}{|c|c|c|}
\hline Zooids & Colonies & Species \\
\hline $\begin{array}{l}\text { 1. Must be autozooids (not kenozooids, vibracula, } \\
\text { avicularia, etc.) }\end{array}$ & \multirow{8}{*}{$\begin{array}{l}\text { 1. With }>30 \text { ontogenetically } \\
\text { complete autozooids, preferably } \\
\text { many more } \\
\text { 2. Not growing on highly } \\
\text { irregular surfaces } \\
\text { 3. Growth not impeded by } \\
\text { competition with other sessile } \\
\text { organisms or epibionts } \\
\text { 4. Replication of colonies within } \\
\text { species }(\geq 5)\end{array}$} & \multirow{8}{*}{$\begin{array}{l}\text { 1. Should possess clear auto- } \\
\text { zooid margins } \\
\text { 2. Autozooid margins are not } \\
\text { obscured by expansion of } \\
\text { polymorphs (e.g. avicularia) or } \\
\text { frontal budding } \\
\text { 3. Not distorted by e.g. drying } \\
\text { 4. Colonies can achieve large } \\
\text { size (not 'spot' colonies with } \\
\text { determinate growth to small } \\
\text { size) }\end{array}$} \\
\hline 2. From outside zone of astogenetic change & & \\
\hline 3. Not abnormal in size/shape (due to e.g. physical & & \\
\hline damage, biotic interaction, position at or just distal & & \\
\hline $\begin{array}{l}\text { to bifurcation in budding series or local regeneration } \\
\text { following colony fragmentation) }\end{array}$ & & \\
\hline 4. From basal series (not frontally budded) & & \\
\hline $\begin{array}{l}\text { 5. EITHER: Randomly choose } 20 \text { autozooids con- } \\
\text { forming to zooid rules } 1-3\end{array}$ & & \\
\hline $\begin{array}{l}\text { 6. OR: Measure successive generations of autozooids } \\
\text { conforming to zooid rules } 1-3 \text { (zooid profiling) }\end{array}$ & & \\
\hline
\end{tabular}


the average zooid lengths of Cryptosula pallasiana from south Wales were significantly longer in July than in January, although there was no significant difference in zooid width (Amui-Vedel et al. 2007). These field results counter the zooid size-temperature relationship that was observed for C. pallasiana in controlled laboratory studies (see 'Laboratory studies'), implying that factors other than temperature may have influenced zooid dimensions. O'Dea \& Jackson (2002) analysed the growth of free-living cupuladriid bryozoans from tropical American regions that experienced strong seasonal upwelling with closely related species from non-upwelling environments. They adopted the zooid size profiling approach to characterise the sizes of zooids in successive generations in a colony (Fig. 4). Strong cyclical patterns of increasing zooid sizes were characteristic of colonies that experienced the seasonal flux of cold water associated with upwelling, when temperatures can drop by $>10^{\circ} \mathrm{C}$ within $1 \mathrm{wk}$ (D'Croz \& O'Dea 2007; see also Fig. 1). In contrast, colonies from non-upwelling environments revealed no significant variation in zooid size throughout their zooid size profiles.

In addition to those studies that compared zooid size directly with temperature, there are several that have done so indirectly, including an early observation that led to the development of the zooid size MART approach (Okamura 1987). Autozooids of Electra pilosa were observed to vary in size over the year in the Menai Straits, North Wales. The evidence was derived by dividing the total number of zooids per colony by colony size, allowing an estimate of mean zooid size per colony at different times of the year (Okamura 1987). Zooid size appeared to be inversely related to temperature, with smaller zooids produced during the warmer summer months. There was no apparent link between zooid size and productivity (e.g. spring and autumn phytoplankton blooms in the Menai Straits; Jones \& Spencer 1970, Al-Hasan et al. 1975).

Other studies have taken a related approach using zooid densities as a proxy for size. O'Dea \& Okamura (2000a) exploited the production of annual growth lines in the upright bifoliate species Flustra foliacea to temporally constrain measures of zooid densities in colonies from Wales, Denmark and Nova Scotia. They found that zooid densities varied cyclically throughout the year in apparent synchrony with seasonal variation in temperature, such that the lowest densities and hence the largest zooids occurred during the cooler spring and autumn periods. Records of planktonic primary productivity, in particular the bimodal spring and autumn phytoplankton blooms that characterise the Menai Straits and the Skagerrak (Pettersson 1991, Blight et al. 1995), indicated that food availability could not have significantly affected zooid size. O'Dea (2005) investigated how zooid densities in a colony of the upright bifoliate species Pentapora foliacea related to stable oxygen isotope data gathered during a previous investigation by Pätzold et al. (1987). The study demonstrated covariation between zooid density and contemporaneous $\delta^{18} \mathrm{O}$ values derived from analyses of zooid skeletal walls, such that lower densities, and hence larger zooid sizes, were associated with higher $\delta^{18} \mathrm{O}$ values indicative of cooler waters (O'Dea 2005).

\section{Geographical variation in the present day}

Geographical variation in zooid sizes has been noted for the encrusting, cave-dwelling species Haplopoma sciaphilum, which produces large zooids in Sweden where it is colder, smaller zooids in the North Adriatic where it is warmer, and yet smaller zooids in France where it is warmest (Silén \& Harmelin 1976). Similarly, mean zooid lengths of Pentapora fascialis showed a significant and negative correlation with mean annual temperature for colonies collected from 9 sites in the Mediterranean and the UK (Lombardi et al. 2006). Conversely, Novosel et al. (2004) found no systematic differences in zooid lengths between 2 sites in the North and South Adriatic that could be explained by temperature. Their study was highly inclusive, analysing 14 cheilostome species. However, the sites were each characterised by varying and complex environmental regimes, including fluctuating salinities at 1 site due to large freshwater inputs via the Zrmanja River and an underground system of karst canals acting as temporary freshwater springs. Substantial fluctuations in salinity are likely to have confounded the zooid size response to temperature (see 'Confounding factors' below). Furthermore, the wholly inclusive random selection of zooids for measurement, without due care, may have resulted in measures of zooids with aberrant growth or those from the zone of astogenetic change. This may explain why the authors were required to adopt a non-parametric approach to analyses since occasional large variances in zooid length would be expected if early stage or distorted zooids were inadvertently measured.

\section{Deep-time variation}

Environments vary not only over space but also over time. The first study to explicitly use zooid size in bryozoans to estimate relative changes in seawater temperatures over geological time scales focused on 8 species common to both the Pliocene Coralline Crag Formation in the eastern UK and in the present-day waters around the UK (Okamura \& Bishop 1988). Specimens 
in the collections of the Natural History Museum, London, were identified that provided at least 5 autozooids for measurement that were unobstructed in growth and outside the zone of astogenetic change. Mean zooid sizes were significantly smaller in 5 of the 8 species in the Coralline Crag than the present day, corroborating previous estimates (see Okamura \& Bishop 1988 for references) that the Coralline Crag was deposited in a sub-tropical sea considerably warmer than today (see also Williams et al. 2009 for further evaluation of the Coralline Crag environment). Replicating the same methods and many shared species, A. O'Dea (unpublished data), found that zooid sizes in the younger Pleistocene Red Crag formation were midway between those of the Coralline Crag and modern day, corroborating the inferred slightly warmer conditions of the Red Crag relative to the present day and cooler conditions relative to the Coralline Crag (Head 1998). In contrast, Berning et al. (2005) found that zooid areas were notably smaller in the Late Miocene cheilostomes from the putatively cooler Guadalquivir Basin in the eastern Atlantic than they were in the same species in 2 warmer and nearly coeval Mediterranean assemblages, suggesting that factors other than temperature may have influenced size (e.g. freshwater input from the Guadalquivir River).

\section{Confounding factors}

When applying the zooid size MART technique, it should always be borne in mind that water temperature can be influenced by factors other than seasonal variation, such as upwelling or depth. In these cases, while the bryozoan responses should represent a true indication of temperatures experienced, the minimum and maximum zooid sizes may reflect temperature variation as a result of ocean currents. Systematic sampling of species that produce annual growth lines may provide a means of recognising multiple drivers of zooid size. For instance, this may be the case if successive zooid generations demonstrate $>1$ peak in size over the course of a single year.

Intracolonial zooid size can also be influenced by other environmental factors besides temperature, e.g. by distortion arising from microenvironmental variation such as irregularities of the substratum over which colonies are growing (Boardman et al. 1969) or following injury or abrasion. More pervasive environmental influences on zooid size include variation in food availability, salinity or flow regimes.

There are conflicting results regarding the influence of food on zooid dimensions. For instance, food availability was not associated with variation in zooid size in Electra pilosa and Conopeum seurati in the field (Oka- mura 1987, O'Dea \& Okamura 1999) nor with variation in zooid density in E. pilosa, C. reticulum or Celleporella hyalina in laboratory experiments (Menon 1972, Hunter \& Hughes 1994) or in Flustra foliacea in the field (O'Dea \& Okamura 2000a). However, analysis of morphological responses of E. pilosa in controlled laboratory studies demonstrated that food concentration produced predictable yet non-linear effects on zooid size (Hageman et al. 2009). At very low food levels, stunted colonies with small zooids developed. At low to intermediate food concentrations, zooid sizes increased with food levels up to a threshold food concentration ( 7.51 $\mathrm{\mu g} \mathrm{l}^{-1} \mathrm{chl}$ a) where maximum zooid sizes were produced. At food concentrations above this threshold, zooid sizes diminished and then stabilised at a size smaller than the maximum size observed at the threshold. The magnitude of food-induced variation in zooid size was associated with these zooid size trends. Thus, maximum variance was coincident with the maximum size, and minimum variance was observed for zooids of submaximum size above the threshold food concentration. Intermediate levels of variation were associated with zooids experiencing low to threshold food concentrations.

If the responses of Electra pilosa apply broadly, they imply that food-induced variation in zooid size will be minimal above some threshold food concentration while greater variation in zooid size in response to food levels can be expected at the threshold food concentration and at levels below. These latter concentrations are estimated to be within the range of concentrations reported for the natural environment and typical of waters from which the $E$. pilosa material was originally

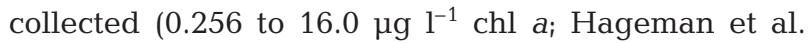
2009). This suggests that variation in food levels may at times confound temperature effects by enhancing or reducing seasonal temperature effects. Previous studies that have reported no effect of food either used food concentrations that were higher than the threshold concentration for E. pilosa, or they did not report food levels. Hageman et al. (2009) therefore speculated that studies revealing no food effect may have been conducted well above the critical value to invoke variation in zooid size.

The study by Hageman et al. (2009) has implications for inferences of temperature regimes made by the zooid size MART approach, with variation in food levels potentially confounding inferred regimes. However, there are several caveats. (1) It is not clear how food-induced changes in zooid size in Electra pilosa when fed an algal monoculture might equate to foodinduced changes in zooid size when a diversity of different food types is available in natural environments. (2) Before the experiment is repeated on other species, it is impossible to discount the possibility that the trends 
observed for E. pilosa may not be universal. (3) Changes in food concentrations from $10^{3}$ to $10^{4}$ cells $\mathrm{ml}^{-1}$ (estimated as equivalent to 1.251 to $12.51 \mathrm{\mu g} \mathrm{l}^{-1} \mathrm{chl}$ a) and from $10^{4}$ to $10^{5}$ cells $\mathrm{ml}^{-1}$ (12.51 to $125.1 \mathrm{\mu g} \mathrm{l}^{-1} \mathrm{chl} \mathrm{a}$ ) were associated with $+14.8 \%$ and $-2.7 \%$ changes in zooid area, respectively. These effects are much smaller than the effect of temperature on Conopeum seurati, which explained $40.51 \%$ of the variation in zooid size when accounting for variation in food levels ranging from near 0 to $\sim 45 \mathrm{~g} \mathrm{l}^{-1} \mathrm{chl}$ a (O'Dea \& Okamura 1999).

As discussed earlier, oxygen may also influence zooid size and indeed may provide a mechanistic explanation for the temperature-size rule. The majority of shallow water and shelf environments that support bryozoan growth can generally be expected to be near oxygen saturation at any given temperature due to atmospheric mixing and photosynthesis. This indicates that the systematic variation between seawater temperature and oxygen content should not be confounded by e.g. oxygen depletion as a result of biological processes that might indirectly influence zooid size. However, the effects of salinity are potentially more complicated due to the inverse relationship between oxygen concentration and salinity levels. This relationship prompted O'Dea \& Okamura (1999) to conclude that salinity, probably as a result of its effect on oxygen solubility, significantly influenced zooid size in Conopeum seurati, accounting for $21.13 \%$ of the variation in zooid size. However, Spicer \& Gaston (1999) highlighted that oxygen partial pressure drives the diffusion gradient in organisms (along with respiratory pigments). At higher salinities, oxygen solubility will be reduced, but the oxygen partial pressure should not be affected. Thus, the changes in zooid size in C. seurati $(21.13 \%)$ may be caused by the direct effect of salinity rather than the covariance of salinity and oxygen solubility (or concentration). In any case, the fact that O'Dea \& Okamura (1999) retrieved temperature as the most significant factor in driving zooid size even under temperate estuarine conditions suggests that salinity effects may rarely swamp temperature effects if temperature and salinity generally covary.

Flow regime can also influence zooid size. A field transplant study in the relatively simple hydrodynamic regime of the Rapids at Lough Hyne, Ireland, demonstrated that zooids of Membranipora membranacea decrease in size with increasing flow (Okamura \& Partridge 1999). The equivalent growth rates of colonies regardless of flow provided evidence that flowinduced miniaturisation may enable effective suspension feeding by creating favourable flow microenvironments. This may be achieved by size alterations that place lophophores into slower flow regimes of the boundary layer, thereby avoiding excessive flows that are detrimental to feeding (Okamura 1985, Eckman \& Okamura 1998).

Finally, a number of studies have demonstrated that zooid size variation is influenced by genotype. This has been shown in laboratory studies of Celleporella hyalina and Electra pilosa (Hunter \& Hughes 1994, Atkinson et al. 2006, Hageman et al. 2009). Genotype has also been inferred to influence zooid size amongst sexually produced colonies that developed under field conditions, accounting for $3.16 \%$ of the variation in zooid size of Conopeum seurati (O'Dea \& Okamura 1999). Such variation demonstrates the variation in thermal reaction norms amongst individuals referred to earlier, and which, for instance, would allow selection and conformation to Bergmann's Rule.

\section{ZOOID SIZE MART APPROACH: APPLICATIONS AND INSIGHTS}

The zooid size MART approach has been applied to several situations to interpret palaeoenvironmental conditions. Estimates of MART from encrusting cheilostomes from the Pliocene Coralline Crag and the Miocene 'Faluns' (O'Dea \& Okamura 2000b) suggest that northwest European seas were considerably more equable (less seasonal) than they are today, a conclusion upheld by open ocean palaeoenvironmental proxies and oceanic modelling from these times (e.g. Cronin \& Dowsett 1996, Lécuyer et al. 1996, Knowles et al. 2009 and references therein). More recently, the zooid size MART approach has been applied for the first time across broad spatial scales focusing on the Pliocene North Atlantic, especially on the time in and around the mid-Pliocene warm period (Knowles et al. 2009). Cheilostome assemblages from the Coralline Crag Formation (UK), the Yorktown Formation (Virginia, USA), the Duplin Formation (South Carolina, USA), the Lower Tamiami Formation (Florida, USA) and the Cayo Agua Formation (Panama) were used to reconstruct MART estimates and to investigate patterns of heat transferral from equatorial to mid-latitude regions. Knowles et al. (2009) corroborated previous evidence for upwelling in the southern Caribbean and in Florida. Their study also indicated that the warm current flowing northeast from the Caribbean resulted in reduced seasonality along the eastern seaboard of the USA, and that it was deflected across the Atlantic further north from the Cape Hatteras area of North Carolina where it is deflected today. The study also showed that seasonal variation in the southern North Sea was greater than that experienced today.

Free-living cupuladriid bryozoans have a rich fossil record in the Caribbean extending back to the time 
before the Isthmus of Panama closed and have been used as key proxies for inferring environmental change during the closure of the Isthmus via the zooid size MART approach. Today, seasonal upwelling brings cool, nutrient-rich waters along the Pacific coast for 3 mo each year (D'Croz \& O'Dea 2007). In contrast, no upwelling occurs along the Caribbean coast (D'Croz \& Robertson 1997). The zooid size MART approach was initially applied to cupuladriids from the presentday by profiling the sizes of zooids from the centre of colonies to their margins (Fig. 4; O'Dea \& Jackson 2002). Strongly fluctuating patterns in zooid size were documented in colonies from the upwelling Gulf of Panama but not in geminate species from the nonupwelling Caribbean coast, and resulting estimates of MART obtained were within an accuracy of $\pm 1^{\circ} \mathrm{C}$ of actual MARTs as derived from multiple oceanographic data (see O'Dea \& Jackson 2002 for references). Subsequent estimates of MART from nearly 150 fossil cupuladriid colonies suggest that strong seasonal upwelling was a permanent feature of the Caribbean when the inter-oceanic Central American Seaway connected the Pacific and Caribbean (O'Dea et al. 2007). The end of upwelling in the Caribbean occurred rapidly during the final stages of isthmus closure, even though the formation of the isthmus was a slow geological process (Coates \& Obando 1996). When the Caribbean became isolated from the Tropical Eastern Pacific, there was a synchronous shift from heterotrophic-dominated to auto- and mixotrophic-dominated benthic communities, consistent with a rapid decline in planktonic productivity and nutrient levels. The high-resolution estimates of upwelling derived from the zooid size MART approach have revealed that 'nutriphilic' coral, bryozoan and molluscan taxa went extinct some 1 to $2 \mathrm{Ma}$ after the end of upwelling, thus challenging the conventional wisdom that cause and effect coincide in deep-time.

Polar material has been the focus of recent zooid size MART analysis. Clark et al. (2010) undertook a pilot study to examine cheilostomes from the Early Pliocene Weddell Sea, Antarctica. Although relatively few colonies were found to meet criteria for analysis, the material provided MART estimates (range $=4.8$ to $10.3^{\circ} \mathrm{C}$ ) that were consistently greater than the seasonal variation in temperature in the present day in the Weddell Sea $\left(2^{\circ} \mathrm{C}\right.$; Whitehouse et al. 1996). Although zooid size MART estimation does not provide an indication of absolute temperatures, the results from this investigation suggest that summer maximum temperatures may have approached or exceeded $8^{\circ} \mathrm{C}$ in the Early Pliocene (given a minimum of $-1.8^{\circ} \mathrm{C}$ when seawater freezes), similar to the present-day seasonal temperature variation in coastal surface waters of southern Patagonia.
Another study used a modified version of the zooid size MART approach to reconstruct MART from fossil cheilostome assemblages of 2 consecutive units of the lower Setana Formation (1.2 to 1.0 Ma, Kuromatsunai, Hokkaido, Japan; Dick et al. 2007). A 'specimenlimited MART' (SL-MART) approach was developed that simulates additional MART estimates from available data to enable use of small datasets when few specimens are available for study. The results suggested more pronounced seasonality in the lower than in the upper Setana Formation, but it was concluded that greater sample sizes were advisable for reconstruction of palaeoseasonality. The SL-MART technique is therefore perhaps best used as a means of gaining preliminary insights into palaeoenvironmental conditions.

In a very recent study, Knowles et al. (2010) undertook the first investigation to examine how results from the zooid size MART approach and stable isotope analyses relate to the actual measured ranges of temperature experienced by cheilostome bryozoans as recorded by a datalogger. They found that the MART implied by zooid size variability in Pentapora foliacea (overall mean of 6.8 and $6.9^{\circ} \mathrm{C}$ at 2 sites in Wales) gave a good approximation to the recorded range in temperature (overall mean range $=7.8^{\circ} \mathrm{C}$, based on a mean minimum recorded temperature of $8.2^{\circ} \mathrm{C}$ and a mean maximum recorded temperature of $16.0^{\circ} \mathrm{C}$ ), while the temperature ranges reconstructed by oxygen stable isotopes were narrower. The latter result appeared to reflect secondary skeletal thickening that homogenised the temperature signal by time-averaging. However, the good approximation to maximum recorded temperatures by oxygen stable isotopes (range $=14.8$ to $16.9^{\circ} \mathrm{C}$ ) demonstrated that zooid size variation and stable isotope analyses can provide independent and valuable proxies for inferring temperature regimes, with data from stable oxygen isotopes relating MART values derived from zooid size variation to absolute temperatures.

\section{ADVANTAGES AND LIMITATIONS OF THE ZOOID SIZE MART APPROACH}

The zooid size MART approach offers several advantages. (1) It represents a relatively inexpensive and quick method to infer palaeoclimate regimes. (2) MART values can be used directly as estimates of temperature variation in environments from which the individual colonies were collected. In contrast, estimates of mean zooid size provide no environmental information on their own but require comparisons with mean zooid sizes of colonies from different environments (e.g. as in Okamura \& Bishop 1988, Berning et al. 2005, Lombardi et al. 2006). (3) The approach can be used to charac- 
terise the ecology of present-day environments that are difficult to access or for which relevant temperature data are unavailable. (4) The zooid size MART approach provides information on the environment experienced by an individual colony that can be related to the life history of that individual colony (e.g. allocation to reproduction, defense and growth), thereby enabling direct correlation of life history responses with environmental regimes. We reiterate that bryozoans are the only colonial invertebrates that enable such insights as a result of their unique combination of traits: intracolonial polymorphism, the production of carbonate skeletons and determinate zooid sizes.

Like any technique, the zooid size MART approach has limitations that are important to appreciate. (1) It requires appropriate material for analysis - a necessity inherent to all methods of assessing temperature regimes. (2) Adherence to the set of rules outlined in Table 1 is critical, since violating assumptions of the approach is likely to give misleading results. For instance, ignoring the strict criteria for measurement, such as measuring distorted zooids or zooids within the zone of astogenetic change, will compromise inferences. We have extensively explored how factors other than temperature may influence zooid size, concluding that these are both less pervasive and exert weaker effects than temperature. (3) It assumes that colonies grow throughout the year (or that growth spans the period of maximum and minimum temperatures). Lack of growth during, for instance, periods of low food availability (e.g. in winter) may result in an inferred MART that is lower than the actual temperature.

There are various means of recognising when inferences for MART may be compromised, including aberrant estimates obtained from a small number of colonies. For instance, a species that consistently estimates a smaller MART relative to other species may be ceasing growth during winter periods. This could be indicated by the presence of annual growth check lines (Fig. 5), and such material could then be avoided. Also, zooid size changes resulting from variation in salinity could be misinterpreted to represent temperature effects on size. In environments where temperature and salinity covary, such as in temperate estuarine conditions, temperature appears to exert an overwhelming effect on zooid size variation (O'Dea \& Okamura 1999). However, salinity could be confounding in environments where temperatures remain relatively constant. For instance, coastal salinities may vary due to seasonal rainfall in the tropics or ice melting in polar regions. In such cases, assemblage information may help to inform on the type of environment in which bryozoans lived, with MART values unexpected for such environments suggestive of possible salinity effects.

\section{RECOMMENDATIONS FOR FUTURE STUDIES}

The foregoing discussion has reviewed the development and application of the zooid size MART approach and the negative relationship between zooid size and temperature that provides the foundation for the approach. Here we suggest future areas for research to address outstanding questions and to identify extensions and further developments of the zooid size MART approach.

Further exploration of the mechanisms that underlie the zooid size-temperature relationship and its generality is merited. Atkinson et al. (2006) have clearly demonstrated that zooid sizes in Celleporella hyalina can be influenced by both temperature and oxygen levels. Are such responses general amongst cheilostome bryozoans? Is there an adaptive basis for the size change, and how might understanding this help us to interpret size variation over time and space? Their finding that colony volumes do not conform to the temperature-size rule is intriguing, as it suggests that zooids, but not colonies, are the units that show equivalent responses to those displayed by solitary organisms. Does this vary amongst species according to their degree of colony integration or mode of life? Do zooids in poorly integrated colonies (e.g. uniserial runners that lack zooid polymorphism) show stronger temperature-induced variation in zooid size than zooids in highly integrated colonies (multiserial forms with a high degree of zooid polymorphism)?

The body of evidence to date suggests that cheilostome zooids generally respond to temperature. Nevertheless, phylogeny can influence many organismal responses (Harvey \& Pagel 1991), and temperature-induced zooid size variation has been demonstrated for relatively few cheilostome species.

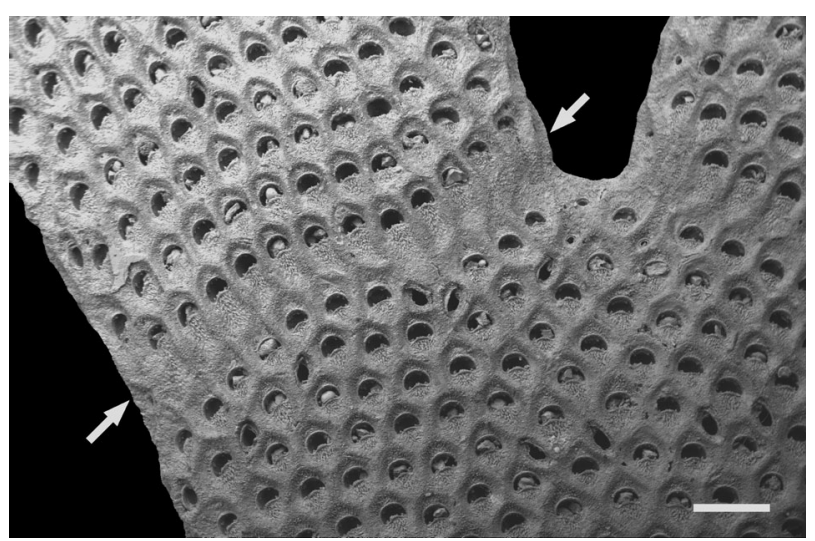

Fig. 5. Melicerita sp. Growth cessation during the winter. Scanning electron micrograph of a fragment from the Coralline Crag Formation (Suffolk, UK) showing skeletal thickening typical of an annual growth check line (white arrows). Scale bar $=250 \mu \mathrm{m}$ 
Although the apparent ubiquity of the temperaturesize rule suggests that phylogeny will play a minor role, further investigation is warrented. If phylogenetic history proved important in determining how zooids respond to temperature, then more strategic sampling and analyses would be advisable. For instance, analyses could be adopted to deal with correlated evolution as a result of common phylogenies (Harvey \& Pagel 1991), and taxa could be targeted or avoided to minimise phylogenetic constraints (Gould \& Lewontin 1979).

Exploring whether an approach based on temperature-induced variation in module size can be extended to other groups could prove to be highly productive and might provide key insights on very ancient environments. Cyclostome bryozoans are the most obvious candidate for such exploration, although their mode of growth would require focusing on different character(s) for measurement (e.g. the aperture). If cyclostomes proved applicable, the use of the zooid size MART approach to reconstruct ancient environments might be extended from the Upper Jurassic (155 Ma; when cheilostomes originated) to the Lower Ordovician (480 Ma; when cyclostomes originated).

Finally, refinement of the zooid size MART approach might enable more accurate and powerful estimates of temperature regimes (Dick et al. 2007). This could certainly be achieved by increasing the number of data points in the model to incorporate more species and to extend geographic cover. It could be argued that more accurate estimates might be gained by more precise measurements of zooid size. For instance, a pilot study confirmed that greater precision can be gained through length and width measurements obtained from scanning electron microscopy (SEM) since SEM images can reduce error in size estimation relative to measurements made using a stereomicroscope (Knowles 2009). However, a requirement to use SEM images for measurement is not warranted for 3 reasons. (1) It would then be advisable to develop a new model using SEM-based measurements. (2) A highly attractive aspect of the zooid size MART approach is that it is easy, inexpensive and requires only standard laboratory equipment. (3) The reliability (e.g. regression model with $95 \%$ confidence limits within $\pm 1^{\circ} \mathrm{C}$ ) and accuracy (e.g. concordance with known temperature regimes or other proxies) of the zooid size MART approach appears to us very reasonable in view of background noise inherent to both new data and the model. We note, however, that SEM images can be very helpful to delineate zooid boundaries, particularly in fossil specimens (e.g. Knowles et al. 2009), and for this reason, making measurements on SEM images can be highly justified as a means of improving data collection.

\section{CONCLUSION}

Our review demonstrates a strong and growing body of evidence that the zooid size MART approach is a unique and independent proxy for environmental reconstruction. The above-described investigations of bryozoan growth in laboratory and field conditions are nearly unanimous in confirming the inverse relationship between zooid size and temperature. Furthermore, the apparent ubiquity of the temperaturesize rule lends additional support. Temperature consistently provides, either directly or indirectly, a pervading and dominant influence on zooid size. The potential for other environmental factors to influence size should nevertheless always be borne in mind when using the zooid size MART approach. However, incorporating other proxies may help to deal with such confounding factors, and palaeoenvironmental reconstruction is considerably strengthened when multiple independent proxies are used. Cheilostomes may provide further potential in this respect, since studies indicate the feasibility of combining the zooid size MART approach with stable isotope analyses of the same specimens (O'Dea 2005, Knowles et al. 2010), provided the mineralogy of the specimens has been well constrained (Smith et al. 2004) and diagenesis is absent (T. Knowles et al. unpubl. data).

We conclude that the zooid size MART approach represents a robust proxy for environmental reconstruction that warrants equal consideration for use as that given to traditional proxies such as stable isotope analyses or alkenones. In addition, because the zooid size MART approach entails sampling over discrete periods of time, insights into the actual annual temperature range are possible. In this respect, the approach offers equal or greater precision than analyses of traditional proxies based on combined samples deriving from a number of years (e.g. geochemical signals from foraminifera) and which may be further compromised by bioturbation. Furthermore, because it is a relatively inexpensive and quick method, the zooid size MART approach can provide a means of gauging environmental variation and of identifying where or when more expensive proxies might be adopted. It therefore merits broad recognition by environmental and evolutionary biologists and climate modellers. Finally, its incorporation in multiproxy toolkits used in palaeoenvironmental research will enable more robust interpretations. Ultimately, such multiproxy-based research with strategic focus on palaeoclimate change will enable better understanding and prediction of how the earth system has responded in the past and how it may therefore respond to future climate change. 
Acknowledgements. We thank P. Taylor for support in the development and application of the zooid size MART approach and for greatly facilitating our research over the years; M. Williams, a non-bryozoologist who recognised the potential of the zooid size MART approach and has enthusiastically championed its use; R. Hughes and J. Jackson for inspiration and insights on the evolutionary ecology of modular animals; S. Hageman for discussion, R. Dewel for the SEM image used for Fig. 1; and 3 reviewers for comments that helped to improve our manuscript. Our research has obtained funding and support from the Natural Environment Research Council, the Biotechnology and Biological Research Council, the Smithsonian Tropical Research Institute and the Natural History Museum.

\section{LITERATURE CITED}

Al-Hasan RH, Coughlan SJ, Pant A, Fogg GE (1975) Seasonal variations in phytoplankton and glycolate concentrations in the Menai Straits, Anglesey. J Mar Biol Assoc UK 55: 557-565

- Amui-Vedel AM, Hayward PJ, Porter JS (2007) Zooid size and growth rate of the bryozoan Cryptosula palliasiana Moll in relation to temperature, in culture and in its natural environment. J Exp Mar Biol Ecol 353:1-12

Angilletta MJ Jr, Steury TD, Sears MW (2004) Temperature, growth rate, and body size in ectotherms: fitting pieces of a life-history puzzle. Integr Comp Biol 44:498-509

Atkinson D (1994) Temperature and organism size: a biological law for ectotherms? Am Nat 162:332-342

> Atkinson D, Morley SA, Hughes RN (2006) From cells to colonies: At what levels of body organization does the 'temperature-size rule' apply? Evol Dev 8:202-214

Berning B, Moissette P, Betzler C (2005) Late Miocene Bryozoa from the Guadalquivir Basin (SW Spain): eastern Atlantic and western Mediterranean environment and biogeography. In: Moyano HI, Cancino JM, Wyse Jackson PN (eds) Bryozoan studies 2004. Balkema, Leiden, p 15-24

Berrigan D, Charnov EL (1994) Reaction norms for age and size at maturity in response to temperature: a puzzle for life historians. Oikos 70:474-478

Bishop JDD (1989) Colony form and the exploitation of spatial refuges by encrusting Bryozoa. Biol Rev Camb Philos Soc 64:197-218

Blight SP, Bentley TL, Lefevre D, Robinson C, Rodrigues R, Rowlands J, Williams PJL (1995) Phasing of autotrophic and heterotrophic plankton metabolism in a temperate coastal ecosystem. Mar Ecol Prog Ser 128:61-75

Boardman RS, Cheetham AH (1969) Skeletal growth, intracolony variation, and evolution in Bryozoa. J Paleontol 43:205-233

Boardman RS, Cheetham AH, Cook PL (1969) Intracolony variation and the genus concept in Bryozoa. Proc North Am Paleontol Conv 1969:294-320

> Chapelle G, Peck LS (1999) Polar gigantism dictated by oxygen availability. Nature 399:114-115

Clark N, Williams M, Okamura B, Smellie J and others (2010) Early Pliocene Weddell Sea seasonality determined from bryozoans. Stratigraphy 7:199-206

Coates AG, Obando JA (1996) The geologic evolution of the Central American Isthmus. In: Jackson JBC, Budd AF, Coates AG (eds) Evolution and environment in tropical America. University of Chicago Press, Chicago, p 21-56

Cronin TM, Dowsett HJ (1996) Biotic and oceanographic response to the Pliocene closing of the Central American
Isthmus. In: Jackson JBC, Budd AF, Coates AG (eds) Evolution and environment in tropical America. University of Chicago Press, Chicago, p 57-75

> D'Croz LD, O'Dea A (2007) Variation in upwelling along the Pacific shelf of Panama and implications for the distribution of nutrients and chlorophyll. Estuar Coast Shelf Sci 73:325-340

D'Croz LD, Robertson DR (1997) Coastal oceanographic conditions affecting coral reefs on both sides of the Isthmus of Panama. Proc 8th Int Coral Reef Symp 2:2053-2058

Dick MH, Hirose M, Takashima R, Ishimura T, Nishi $H_{\text {, }}$ Mawatari SF (2007) Application of MART analysis to infer paleoseasonality in a Pleistocene shallow marine benthic environment. In: Okada H, Mawatari SF, Suzuki N, Gautam P (eds) Proc Int Symp 'Origin and Evolution of Natural Diversity', 1-5 October 2007, Sapporo, p 93-99

Eckman JE, Okamura B (1998) A model of particle capture by bryozoans in turbulent flow: significance of colony form. Am Nat 152:861-880

Falcon-Lang H (2005) Global climate analysis of growth rings in woods, and its implications for deep-time paleoclimate studies. Paleobiology 31:434-444

Gordon DP, Taylor PD, Bigey FP (2009) Phylum Bryozoa. Moss animals, seamats, lace corals. In: Gordon DP (ed) New Zealand inventory of biodiversity. Vol 1. Kingdom Animalia. Radiata, Lophotrochozoa, Deuterostomia. Canterbury University Press, Christchurch, p 271-297

Gould SJ, Lewontin RC (1979) The spandrels of San Marco and the Panglossian paradigm: a critique of the adaptationist programme. Proc R Soc Lond B Biol Sci 205: 581-598

> Hageman SJ, Needham LL, Todd CD (2009) Threshold effects of food concentration on the skeletal morphology of the bryozoan Electra pilosa (Linnaeus, 1767). Lethaia 42: $438-451$

Hallmann N, Burchell M, Schöne BR, Irvine GV, Maxwell D (2009) High-resolution sclerochronological analysis of the bivalve mollusk Saxidomus gigantea from Alaska and British Columbia: techniques for revealing environmental archives and archaeological seasonality. J Archaeol Sci 36:2353-2364

Harvey PH, Pagel MD (1991) The comparative method in evolutionary biology. Oxford University Press, Oxford

Head MJ (1998) Pollen and dinoflagellates from the Red Crag at Walton-on-Naze, Essex: evidence for a mild climatic phase during the early Late Pliocene of eastern England. Geol Mag 135:803-817

Hunter E, Hughes RN (1994) The influence of temperature, food ration and genotype on zooid size in Celleporella hyalina (L.). In: Hayward PJ, Ryland JS, Taylor PD (eds) Biology and paleobiology of bryozoans. Olsen \& Olsen, Fredensborg, p 83-86

Jones M, Spencer CP (1970) The phytoplankton of the Menai Straits. J Cons Int Explor Mer 33:169-180

Kingsolver JG, Huey RB (2008) Size, temperature, and fitness: three rules. Evol Ecol Res 10:251-268

Knowles T (2009) Fossil cheilostome Bryozoa of the midPliocene North Atlantic and the inference of environmental regimes. PhD thesis, University of Reading

Knowles T, Taylor PD, Williams M, Haywood AM, Okamura B (2009) Pliocene seasonality across the North Atlantic inferred from cheilostome bryozoans. Palaeogeogr Palaeoclimatol Palaeoecol 277:226-235

Knowles T, Leng MJ, Willams M, Taylor PD, Sloane HJ, Okamura B (2010) Interpreting seawater temperature range using oxygen isotopes and zooid size variation in Pentapora foliacea (Bryozoa). Mar Biol 157:1171-1180 
Lécuyer C, Grandjean P, Paris F, Robardet M, Robineau D (1996) Deciphering 'temperature' and 'salinity' from biogenic phosphates: the $\delta^{18} \mathrm{O}$ of coexisting fishes and mammals of the middle Miocene sea of western France. Palaeogeogr Palaeoclimatol Palaeoecol 126:61-74

Lombardi C, Cocito S, Occhipinti-Ambrogi A, Hiscock K (2006) The influence of seawater temperature on zooid size and growth rate in Pentapora fascialis (Bryozoa: Cheilostomata). Mar Biol 149:1103-1109

McKinney FK, Jackson JBC (1989) Bryozoan evolution. Unwin Hyman, Boston

Menon NR (1972) Heat tolerance, growth and regeneration in three North Sea bryozoans exposed to different constant temperatures. Mar Biol 15:1-11

Novosel M, Požar-Domac A, Parasic M (2004) Diversity and distribution of the Bryozoa along underwater cliffs in the Adriatic Sea with special reference to thermal regime. PSZNI: Mar Ecol 25:155-170

O'Dea A (2005) Zooid size parallels contemporaneous oxygen isotopes in a large colony of Pentapora foliacea (Bryozoa). Mar Biol 146:1075-1081

O'Dea A, Jackson JBC (2002) Bryozoan growth mirrors contrasting seasonal regimes across the Isthmus of Panama. Palaeogeogr Palaeoclimatol Palaeoecol 185:77-94

O'Dea A, Okamura B (1999) The influence of seasonal variation in temperature, salinity, and food availability on module size and colony growth in the estuarine bryozoan, Conopeum seurati. Mar Biol 135:581-588

O'Dea A, Okamura B (2000a) Life history and environmental inference through retrospective morphometric analysis of bryozoans: a preliminary study. J Mar Biol Assoc UK 80: $1127-1128$

O'Dea A, Okamura B (2000b) Intracolony variation in zooid size in cheilostome bryozoans as a new technique for investigating palaeoseasonality. Palaeogeogr Palaeoclimatol Palaeoecol 162:319-332

O'Dea A, Jackson JBC, Fortunato H, Smith JT, D'Croz L, Johnson KG, Todd JA (2007) Environmental change preceded Caribbean extinction by 2 million years. Proc Natl Acad Sci USA 104:5501-5506

Okamura B (1985) The effects of ambient flow velocity, colony size, and upstream colonies on the feeding success of Bryozoa. II. Conopeum reticulum (Linnaeus), an encrusting species. J Exp Mar Biol Ecol 89:69-80

Okamura B (1987) Seasonal changes in zooid size and feeding activity in epifaunal colonies of Electra pilosa. In: Ross JRP (ed) Bryozoa: past and present. Western Washington University, Bellingham, WA, p 197-204

Okamura B, Bishop JDD (1988) Zooid size in cheilostome bryozoans as an indicator of relative palaeotemperature. Palaeogeogr Palaeoclimatol Palaeoecol 66:145-152

Submitted: April 27, 2010; Accepted: November 30, 2010
Okamura B, Partridge JC (1999) Suspension feeding adaptations to extreme flow environments in a marine bryozoan. Biol Bull (Woods Hole) 196:205-215

> Pätzold J, Ristedt H, Weger G (1987) Rate of growth and longevity of a large colony of Pentapora foliacea (Bryozoa) recorded in their oxygen isotope profiles. Mar Biol 96: $535-538$

Pettersson K (1991) Seasonal uptake of carbon and nitrogen and intracellular storage of nitrate in planktonic organisms in the Skagerrak. J Exp Mar Biol Ecol 151:121-137

> Pörtner HO (2002) Climate variation and the physiological basis of temperature dependent biogeography: systemic to molecular hierarchy of thermal tolerance in animals. Comp Biochem Physiol A Mol Integr Physiol 132:739-761

Rucker JB, Carver RE (1969) A survey of the carbonate mineralogy of cheilostome Bryozoa. J Paleontol 43:791-799

Ryland JS (1963) The species of Haplopoma (Polyzoa). Sarsia 10:9-18

Silén L, Harmelin JG (1976) Haplopoma sciaphilum sp. n., a cave-living bryozoan from the Skagerrak and the Mediterranean. Zool Scr 5:61-66

Smith AM, Nelson CS, Key MM Jr, Patterson WP (2004) Stable isotope values in modern bryozoan carbonate from New Zealand and implications for paleoenvironmental interpretation. NZ J Geol Geophys 47:809-821

Spicer JI, Gaston KJ (1999) Amphipod gigantism dictated by oxygen availability? Ecol Lett 2:397-401

Van der Have TM, de Jong G (1996) Adult size in ectotherms: temperature effects on growth and differentiation. J Theor Biol 183:329-340

Van Voorhies WA (1996) Bergmann size clines: a simple explanation for their occurrence in ectotherms. Evolution 50:1259-1264

Whitehouse MJ, Priddle J, Symon C (1996) Seasonal and annual change in seawater temperature, salinity, nutrient and chlorophyll a distributions around South Georgia, South Atlantic. Deep-Sea Res I 43:425-443

Williams M, Hayward AM, Harper EM, Johnson ALA and others (2009) Pliocene climate and seasonality in North Atlantic shelf seas. Philos Trans R Soc A 367:85-108

Winston JE, Håkansson E (1986) The interstitial bryozoan fauna from Capron Shoal, Florida. Am Mus Novit 2865: 1-50

Woods HA (1999) Egg-mass size and cell size: effects of temperature on oxygen distribution. Am Zool 39:244-252

Zazzo A, Smith GR, Patterson WP, Dufour E (2006) Life history reconstruction of modern and fossil sockeye salmon (Oncorhynchus nerka) by oxygen isotopic analysis of otoliths, vertebrae and teeth: implications for paleoenvironmental reconstructions. Earth Planet Sci Lett 249: 200-215

Proofs received from author(s): March 1, 2011 